\title{
Big Data and IoT Opportunities for Small and Medium-Sized Enterprises (SMEs)
}

\author{
Siti Aishah Mohd Selamat ${ }^{\# 1}$, Simant Prakoonwit ${ }^{\# 2}$, Reza Sahandi ${ }^{\# 3}$, Wajid Khan ${ }^{\# 4}$ \\ Faculty of Science \& Technology, University of Bournemouth \\ Bournemouth, United Kingdom \\ $\left\{\right.$ aishah, ${ }^{2}$ sprakoonwit, ${ }^{3}$ rsahandi, ${ }^{4}$ wkhan\}@bournemouth.ac.uk
}

\begin{abstract}
:
The advancement of technology and emergence of Internet-of-Things (Woodward, Gray, \& Elliott) has exponentially caused a data explosion in the 21st Century era. As such, the arrival of IoT is set to revolutionize the development of a Small and Medium-Sized Enterprise (SME) organizations - by shaping it into a more universal and integrated ecosystem. Despite evidential studies of the potential of advanced technologies for businesses, the SMEs are apprehensive of new technologies such as big data analytics and IoT. Therefore the aim of this chapter is to provide a holistic study of big data and IoT opportunities, challenges and, applications within the SMEs context. It is with the hope that the outcome of this study would provide foundational information on how the SMEs can partake with the new wave technological advancement - in turn spurring more SMEs for adoption.
\end{abstract}

Keywords: Big Data, SMEs, Big Data Analytic, BDA-IoT

\section{INTRODUCTION}

The advancement of technology and emergence of Internet-of-Things (Woodward et al.) has exponentially caused a data explosion in the 21st Century era. It is predicted that the magnitude of data is set to scale up to fifty billion Terabytes by 2020 (Arora \& Rahman, 2016). The arrival of IoT is set to revolutionize the development of a Small and Medium-Sized Enterprise (SME) organisation - by shaping it into a more universal and integrated ecosystem. The inpouring of data can pose as a potential treasure for the SMEs organisation if the data collected are inherently translated to become useful knowledge (Chudik, Kapetanios, \& Pesaran, 2016). Despite being in a progressive business condition, loaded with interconnectedness; a business long-term positioning remains 'uncertain'. It is, therefore, crucial to study the opportunities of big data and IoT for the SMEs. In addition, analysing also its implications and effect, should the SMEs organization fails to jump on-board on the new technological advancement wave. An extensive report from the European (EU) Commission indicates that SMEs are the core financial driver of growth in the EU region. In 2015, the EU Commission unveils that the SMEs contributed up to approximate of 4 trillionn euros to the EU economy (Eurostat 2018). Further to this, it has been highlighted that the SMEs are contributing twice as much in comparison to the larger organizations available in the EU continents. SMEs organizations can aspect to accelerate their growth by up to two to three times faster when they embrace new digital technologies like big data and IoT (Commission, 2013). The untapped potential here for the SME is really immense. For instance, a recent study by the EU Commission denotes that most 
digitally mature SMEs in France observed a growth rate of up to six times in comparison to the digitally less mature SMEs. By incorporating new technologies into the business, the French SMEs doubled their revenue growth rates (Commission, 2017). Another study conducted in the Swedish context reveals a similar result. Despite the momentous opportunities and advantages, SME businesses are slow to change and labeled as laggards in new technologies adoption in comparison to its larger enterprise counterpart. It is reported that close to 9.2 million (41\%) of EU SMEs have yet to adopt any of a set of the four advanced technologies like social media, mobile, big data and cloud computing. Focusing in specific to the big data solution adoption rate; an alarming figure of 20.7 million EUs SMEs has yet to adopt big data technologies in 2015 (Commission, 2013). These startling findings insinuate that these SMEs will not be ready to welcome the IoT technologies either. Reason being, big data capability is mandatory for connecting into the IoT ecosystem. It would be unattainable for the EU SMEs to manage the incoming data flow from the embedded sensors from the IoT without having the big data solutions in place first. It is undeniable that the EU SMEs needs to revolutionize itself in order to remain competitive and relevant in the business sphere. As recount earlier, the business environment is unpredictable; the EU SMEs unpreparedness could eventually be overtaken by the larger enterprises.

The key objective of the chapter is to outline a holistic research of big data and IoT opportunities, challenges and, applications within the SMEs context. It is with the hope that the outcome of this study would provide foundational information on how the SMEs can partake with the new wave technological advancement - in turn spurring more SMEs for adoption. This chapter would provide a unique contribution to the research handbook by providing the readers with a comprehensive breakdown of big data and IoT study in the SMEs context. The target audience of this chapter is aimed at researchers, business leaders and policymakers' with a special interest in the research and study of SME developments. The contribution of this chapter anticipates in elevating the awareness on the study of big data and IoT, providing aid to the SMEs' understanding and business capitalization. To ensure the relevance and applicability of this chapter, the literature collections are limited to publication within the last 10 years' time period. The literature selection includes papers relating to the SMEs hindrance factors in big data technology application, the potential benefits and advantages of big data and IoT application in the various SMEs industry and the probable challenges and drawback. The literature collected is screened to validate the relevance and applicability of the literature content. Upon the literature screening, only fitting articles are used for this research. The works of literature were cited from credible research databases like Science Direct, Association for Computing Machinery Digital Library, EJS E-Journals, Google Scholar, Springer, Science Direct, Semantic Scholar and last but not least, International Publisher of Information Science and Technology Research. In the next section, this study will provide an overview background of the SME's deterrent factors against big data analytics (BDAs). The third section will identify the additional organisational barriers faced by the SMEs in BDA applications. The fourth and fifth section will present an overview of BDA and IoT subject. This is followed by, a run through of the technology applications within the SMEs context. The sixth and seventh sections will cover the potential benefits and challenges of BDA and IoT applications for SMEs. The eighth section of this chapter will include with a general guideline for SMEs to consider when adopting the BDA and IoT applications. Lastly, this chapter will conclude the overall contribution of this chapter.

\section{SME'S DETERRENT FACTORS AGAINST BIG DATA ANALYTICS (BDA)}

Based on several key research, it is evident that the SME group are skeptic towards new technological adoption - especially so, in the area of BDA application (Mohd Selamat, 
Prakoonwit, Sahandi, Khan, \& Ramachandran, 2018). According to Coleman (2016), there are several key resistant factors towards BDA application. And these key factors can be classified into three components - knowledge, resources and data management. The illustration of each component (knowledge, resources and data management) will be discussed in the next subsections. The discussion will include research examples to support and justify the three individual components.

\subsection{RESOURCES}

One of the major obstacles of the SMEs in adopting the BDA technology relates to resources. The reason includes (1) the shortfall in financial source to invest in the used of brand-new technologies (2) the limitation in the value for money analytics consulting solution available for SMEs (3) the lack and shortage of internal data analytics professional within the SMEs domain and lastly (4) the analytics software package available in the market is highly complex. First and foremost, the shortfalls of capable, adequate and licensed BDA specialist in the market generate the paucity of in-house experts in the BDA domain. Within the United States of America (USA) it is predicted and envisage that by year-end 2018, there will be an estimated of two hundred thousand deficit of proficient analytics talent and a further close to an additional one and half million analytics senior executive equipped with the suitable proficiency to make strategic business decision(s) with big data (Manyika et al., 2011). In a study conducted with the UK recruiters, it is revealed that an estimate of $60 \%$ of the recruiting agent is experiencing talent scarcity in the BDA domain (UK, 2013)This would evidently have a great implication in the BDA evolvement within the EU context. The available analytics software in the market is expected to curb the impending deficit of BDA talent supply. Although there is plenty of analytics solution readily available for the SMEs purchase - to narrow down a feasible solution that is installed with robust and user-friendly analytic functions is sparse. The requirement of a simple and straightforward user interface would facilitate a shorter learning experience and in turn, enabling a quicker technology implementation time frames (Probst et al., 2014). Additionally, the end users will little or nil proficiency in the technology may face difficulties in choosing the right analytics solution given that the evaluation platforms provided by the vendor are vendor biased. A lower price-performance ratio solution in the market would ease the impending financial resource limitation of the SMEs (S. Coleman et al., 2016).

\subsection{KNOWLEDGE}

The second key obstacles faced by the SMEs in BDA technology application are associated with knowledge elements such as (1) the lack of comprehension in the BDA domain (2) minimal interest in new upcoming management trends in the business sphere and lastly, (3) the inadequacy and availability of successful SMEs case studies to make reference of. The lack of comprehension in the BDA domain by the SMEs' staff can be seen in the UK (UK, 2013) and Germany (S. Y. Coleman, 2016) based on a survey conducted by two separate researches. Notably, the SMEs at large are unaware of the potential residing within the business datasets, in consequence, creating doubt on the BDA capabilities to derive the expected advantages from it. Although there are general guidelines for the SMEs to refer to, there are little or nil exemplary research case studies of successful BDA implementation in the SMEs context (Mohd Selamat et al., 2018). The current BDA case studies collected in the EU context does not generally correspond with the SMEs' needs as the use cases are in relation to the larger enterprises. Given that the function and operation of the SMEs differ greatly to the larger organization, the availability of more case studies in the SME context is needed to boost the SMEs zeal in BDA adoption.

\subsection{DATA MANAGEMENT}


The last obstacles component encountered by the SMEs relates to data management. The SMEs stakeholders have concerns regarding data security, protection and privacy. In a global survey conducted, out of the 82 SMEs organizations surveyed, more than half percent of the organizations had identified data protection and security has a key concern and barrier to BDA application (S. Y. Coleman, 2016). Unlike the larger organizations, the SME group in totality lacks the aptitude and capability to build up its information technology safety measure (Lacey \& James, 2010). The current usage in regards to the outdated database management system by the SMEs may make them more vulnerable against intrusions and cyber-attacks. In addition, SMEs in the EU continent will need to abide by the EU data regulation (Rights, 2016) on data privacy and protection when managing its customer's data. In view of the lengthy EU data protection law and that the SMEs has financial constraint, the SMEs would not be able to supplement the financial expense in engaging a legal expert to administer the legality aspect of EU data legislation requirements.

\section{ADDITIONAL ORGANISATIONAL BARRIERS}

Apart from the barrier in association to resource, knowledge and data management, it is worthy to note that there are other incorporeal drawbacks that are preventing the SMEs from applying the BDA initiative in its business. These barriers are in relation to the SMEs' internal management matters such as organisational culture, structure and decision-making. Although these matters are elusive in nature, its impact and implication are paramount to the SMEs. In the area of organisational culture - customary, the SMEs leaders have minimal or zero engrossment in contemporary and emerging executive trends that could be useful to the organisation (Goebel, Norman, \& Karanasios, 2015). As such, the inherent traditionalism value of the SMEs' leaders perceives the application of BDA as rising business hype only. The second organisational barrier relates to the SMEs' management structure, whereby a felicitous management formation is needed in order to have a fluent BDA executive. Traditionally, unlike the larger organisations, a majority of the SMEs organisational hierarchy are flat with minimal or zero middle authority amongst the general staffs and executive employees (Capgemini, 2012). How SMEs are being organised will impact the way in which decisions are being made. Generally, in the SMEs environment, the business owners are usually the decision makers. How the business owners make their decisions are occasionally mirrored by the individual's life and identity (Goebel et al., 2015). The presence of a hierarchical structure in the larger organization makes the decision making the process more rational in comparison to the SMEs, which are mainly driven by the company owner's instinct or experiences (Culkin \& Smith, 2000). In summation, should business owners are not personally inclined towards learning and keeping him or herself updated with the new management trends of BDA - it will pose a great challenge to overcome.

\section{BDA AND INTERNET OF THINGS}

BDA is at present gaining momentous attraction globally. As defined by Gartner, big data refers to the high volume, velocity, variety of information assets that require processing in order to churn out new and unique insights to facilitate strategic decision making and process optimization (Beyer, 2011). Adding additional Vs of veracity; variability and value proposition to the initial 3Vs (Lugmayr et al., 2016) - the consolidation of first five Vs (volume, velocity, variety, veracity, and variability) would provide the final $\mathrm{V}$ of value proposition, which is important for all organizations. The emergence of big data has created a great demand for companies to engage data scientists that are equipped with the relevant skills to analyse and churn out unique business insights from various data source pool (Bagnoli, 2015). For the organization to deliver a successful analytics undertaking - they are seven key factors to take note of. The seven factors consist of (1) a well-defined business needs (2) a solid and committed 
benefactor (3) a clear calibration of the business and technology strategy (4) a data-driven decision making business culture (5) a well-founded data structure (6) the relevant appropriate analytical contrivance and lastly, (7) a group of well-skilled employees in the analytical domain (Turban, King, Sharda, \& Delen, 2013). In summary, to build a data-driven organization, both the technical and organisational needs are required to be in place in order to implement the BDA undertakings successfully. Big data then comes in various sources, which are considerably big in volume and are generally in actual-time environment. The trend is shaping broadly from the presence of mobile phones and social media gadgets. The IoT platform on the other hand are driven with the presence of radio frequency identification (RFID) and the various sensor or tracking medium (Strohbach, Ziekow, Gazis, \& Akiva, 2015). IoT is commonly defined as the global network and chain of interconnected gadgets, which are uniquely identified, based on the common communication protocols (Y. Sun, Song, Jara, \& Bie, 2016). It is predicted that the volume of connected on IoT is estimated to reach 75 billion by the year 2020 (Shanthamallu, Spanias, Tepedelenlioglu, \& Stanley, 2017). The presence of IoT will become pervasive in the coming years, generating a massive volume of data. As such, these data are needed for analysis in order to create value for a particular organization or society. The function of IoT would facilitate the tracing and tracking of all tagged mobile devices as it maneuvers around or is in a stationary position to audit its changeable environment. This could include object going through the supply line of chain, devices, and machinery in the hospital or factory setting or lastly, even a self-driving automobile. Stationary objects with embedded control and sensor capabilities that are connected to the IoT are able to (1) oversee its overall circumferential surrounding (2) carry out conditional reporting (3) change its state and the state of any connected devices and lastly (4) make amendments to its encompassing environment (Lee \& Lee, 2015). The predicted 75 billion connected objects as envisioned by Morgan Stanley - would indefinitely provide momentous strategic and operational benefits for an organization that is capable to take advantage of the IoT technology functionality. In order to effectively manage the IoT automation demands, BDA is required to collect, converge and analyse the data streaming from the various sources such as sensors, RFID tags, social media feeds, video, images and mobile devices (Riggins \& Wamba, 2015). It is evident that the role of BDA and IoT can spur tremendous opportunities for organization of the various industries.

\section{OPPORTUNITIES OF BDA AND IOT}

Through this chapter, two opportunities of IoT platform have been identified (as refered in Table 1) - cyber-physical cloud computing (CPCC) and mobile crowdsensing (MCS). The illustrations of both platforms are as follows:

\section{Table 1. IoT Platform Opportunities}

\begin{tabular}{|l|l|}
\hline $\begin{array}{l}\text { Mobile Crowdsensing } \\
\text { (MCS) (Ganti, Ye, \& } \\
\text { Lei, 2011) }\end{array}$ & $\begin{array}{l}\text { Mobile crowdsensing (MCS) makes up one class of the IoT } \\
\text { application that depends heavily on the data collected from an } \\
\text { extensive volume of mobile sensing gadgets such as mobile } \\
\text { phones. The MCS application can be classified into three different } \\
\text { groups - (1) social (2) infrastructure and (3) environmental. } \\
\text { Within the social MCS applications, individuals are sharing } \\
\text { sensed information amongst themselves. For an instance, an } \\
\text { individual can be sharing about their personal exercise data and } \\
\text { compare their personal exercise data amongst the entire } \\
\text { community. This would assist the individual to improve their } \\
\text { exercise routines. Within the environmental MCS applications, }\end{array}$ \\
\hline
\end{tabular}




\begin{tabular}{|c|c|}
\hline & $\begin{array}{l}\text { data of the concerning the natural environment are measured. For } \\
\text { instance, measuring the noise or air pollution levels in a particular } \\
\text { city. Within the infrastructure MCS applications, data of the public } \\
\text { infrastructure are being measured. For instance, the traffic } \\
\text { congestion, condition, power outage, parking vacancy and transit } \\
\text { tracking are being measured. The benefits of MCS include: } \\
\text { - Having significantly large storage, communication and } \\
\text { computation are fitted with multimodality sensing } \\
\text { functionalities } \\
\text { - Preventing high deployment cost and time of setting up big- } \\
\text { scale wireless sensor networks. In the } 21^{\text {st }} \text { century, it is } \\
\text { normality for the majority of the individuals to be carrying } \\
\text { their mobile devices. }\end{array}$ \\
\hline $\begin{array}{l}\text { Cyber-Physical Cloud } \\
\text { Computing (CPCC) } \\
\text { (Colombo et al., 2014) }\end{array}$ & $\begin{array}{l}\text { Cyber-Physical Could Computing (CPCC) refers to a networking } \\
\text { framework for cyber-physical systems (CPS). CPS refers to smart } \\
\text { networked systems with integrated sensors, actuators and, } \\
\text { processors that are constructed to interact and sense with the } \\
\text { human users and also, support real-time safety-critical } \\
\text { applications. The benefit of CPCC includes the effective usage of } \\
\text { resources, smart adaption to the environment in every scale, } \\
\text { reliable and resilient. The CPCC paradigm plays an integral role } \\
\text { in the smart city infrastructure like smart transportation, smart } \\
\text { disaster management, smart healthcare and many more. }\end{array}$ \\
\hline
\end{tabular}

The accumulations of a large volume of data collected through the IoT platform present the utilization of BDA application to process analysed and interpret the collected data for strategic decision-making and control.

\section{CHALLENGES OF BDA AND IOT}

In regards to the challenges, two probable challenges of IoT has been identified (as refered in Table 2)- resource limitations and cyber security and privacy. The illustrations of both challenges are as follows:

Table 2. IoT Probable Challenges

\begin{tabular}{|l|l|}
\hline $\begin{array}{l}\text { Resource Limitations } \\
\text { (Van Kranenburg \& } \\
\text { Bassi, 2012) }\end{array}$ & $\begin{array}{l}\text { The mobile devices collecting the sensor data are high-powered in } \\
\text { its capabilities and availability as such, predicting the bandwidth } \\
\text { and energy requirement in an IoT application is challenging. } \\
\text { Additionally, scheduling and identifying communication and } \\
\text { sensing tasks amongst the large volume of devices with the wide } \\
\text { variation of sensing functionalities can be a very daunting task. }\end{array}$ \\
\hline $\begin{array}{l}\text { Cyber Security and } \\
\text { Privacy } \\
\text { (Zhou, Cao, Dong, \& } \\
\text { Vasilakos, 2017) }\end{array}$ & $\begin{array}{l}\text { The second key challenge in an IoT application is the preservation } \\
\text { of the individual's personal privacy and security - from which } \\
\text { sensitive data in relation to the individual are being collected } \\
\text { through sensors. For an instance, GPS sensor data, which are used } \\
\text { to gauge the traffic condition level, can also be used to read } \\
\text { personal information of the individual's daily route to work, home }\end{array}$ \\
\hline
\end{tabular}




\begin{tabular}{|l|l|}
\hline & $\begin{array}{l}\text { or social meet-up locations. As such, the security and privacy } \\
\text { regulation can implicate the access management of data records } \\
\text { within and across the IoT services. }\end{array}$ \\
\hline
\end{tabular}

Most often, the data collected through the IoT platform are diverse and heterogeneous in state. For an instance, data in relation to smart buildings does not consist only the energyconsumption data, weather data, but in addition, the data on the thermostat settings, the state of the windows and doors, airows, room occupancy, building materials and structure and many more. Therefore, translating social variable, biological and physical into a concise and indicative electrical signal is a demanding task. For an instance, occupancy in a building can be obtained from appliance acoustics, usage, infrared signatures, motion detection, vibration, imaging, disruption and many other - but in all, these only serve as noisy indicators of room occupancy (Lee \& Lee, 2015)

\section{BDA AND IOT APPLICATION FOR SMES}

The BDA and IoT application is not only limited to the large organization but rather, it also provides tremendous opportunities for SMEs too. The SMEs can be equivalently competitive and yet remaining small by channeling its focus over technology and applications over its headcount. The opportunity to tap on both the BDA and IoT capabilities is limitless. As illustrated below are several use cases on how BDA and IoT can be applied in the SMEs' industrial practice of various areas - as refered in Table 3.

Table 3. SMEs Industrial Applications

\begin{tabular}{|l|l|}
\hline Area & Application \\
\hline $\begin{array}{l}\text { Product Design and } \\
\text { Heppelmann, 2014) }\end{array}$ & $\begin{array}{l}\text { The sensor functionality can aid in reporting how, when and } \\
\text { where a particular product is being used - providing valueable } \\
\text { inputs to designing and marketing process. The channel for } \\
\text { collecting real-time data can provide the business a more } \\
\text { effective and accurate information in comparison to the } \\
\text { traditional customer survey or market research. }\end{array}$ \\
\hline $\begin{array}{l}\text { Product Sales (Perera, Jayawardena, \& } \\
\text { Chen, 2014) }\end{array}$ & $\begin{array}{l}\text { Through monitoring the inventory and usage of a particular } \\
\text { product or connected elements - the SMEs can preempt when } \\
\text { the customers will need a supplement order or parts. The SMEs } \\
\text { sales department will then need to ensure that the required } \\
\text { products are available in the inventory stock. By having the } \\
\text { relevant information readily at hand, the sales department can be } \\
\text { proactive in its delivery in order to avoid any potential loss of } \\
\text { revenue to the competitors. }\end{array}$ \\
\hline $\begin{array}{l}\text { Product Maintenance } \\
\text { Tao, Cheng, Da Xu, } \\
\text { Zhang, \& Li, 2014) }\end{array}$ & $\begin{array}{l}\text { In relation to product maintenance, real-time data on operational } \\
\text { wear and tear can enable in reducing operating and maintenance } \\
\text { cost by identifying in advance possible equipment failure. This } \\
\text { is would, in turn, avoid at downtime period in the organization } \\
\text { operational activities. For an instance, in a printing business, if } \\
\text { one of the machines were to break down during a print run, the } \\
\text { business could a substantial amount of monetary loss. And this } \\
\text { including incurring additional cost to request for emergency }\end{array}$ \\
\hline
\end{tabular}




\begin{tabular}{|c|c|}
\hline & $\begin{array}{l}\text { servicing request in an emergency situation. In overall, this } \\
\text { would implicate the service delivery timeline for the customer - } \\
\text { if the delivery is delayed, the business will need to compensate } \\
\text { the customer accordingly. Potential equipment failure can be } \\
\text { deduced by sensing the heat indication or vibration of the } \\
\text { machinery. By doing so, the technician can be primitively } \\
\text { dispatched to avoid a plausible equipment failure. }\end{array}$ \\
\hline $\begin{array}{l}\text { Logistics (C. Sun, } \\
\text { 2012) }\end{array}$ & $\begin{array}{l}\text { For logistic SMEs, the application of sensor in shipping } \\
\text { containers can allow the company to receive real-time data on } \\
\text { the package location and condition. By connecting the real-time } \\
\text { information to the SMEs warehouse management system } \\
\text { (WMS), it would enhance the business efficiencies, service } \\
\text { delivery and boost customer service. }\end{array}$ \\
\hline $\begin{array}{l}\text { Product Engineering } \\
\text { (Perera et al., 2014) }\end{array}$ & $\begin{array}{l}\text { In product engineering, the selection of product design and } \\
\text { material can be improved by monitoring the machine's } \\
\text { condition, configuration and, overall usage. }\end{array}$ \\
\hline $\begin{array}{l}\text { Manufacturing } \\
\text { Processes } \\
\text { (Bandyopadhyay \& } \\
\text { Sen, 2011) }\end{array}$ & $\begin{array}{l}\text { In relation to the manufacturing processes; a potential issue that } \\
\text { impacts the production's output level can be distinguished } \\
\text { earlier so as to schedule the necessary corrective measure. } \\
\text { Monitoring the configuration, condition, and usage of the } \\
\text { production machinery can carry this out. }\end{array}$ \\
\hline $\begin{array}{l}\text { Transportation } \\
\text { (Chunli, 2012) }\end{array}$ & $\begin{array}{l}\text { Within the transportation context, SMEs can provide IoT } \\
\text { services to supplement the smart city initiative. For an instance, } \\
\text { smart parking can be offered to provide driving commuters real- } \\
\text { time update on the parking availability and also enabling the user } \\
\text { to make the parking payment with their mobile phone. In the } \\
\text { context of public transport, real-time update on the transport } \\
\text { arrival and seat availability can be shown on the bus stops } \\
\text { dashboard or mobile application. }\end{array}$ \\
\hline $\begin{array}{l}\text { Fleet Maintenance } \\
\text { (Chen, Xu, Liu, Hu, } \\
\text { \& Wang, 2014) }\end{array}$ & $\begin{array}{l}\text { Under the fleet maintenance, the sensory function can be applied } \\
\text { to monitor the fleet's speed, mileage, and engine health. By } \\
\text { collecting data on the vehicle's condition and usage, an advance } \\
\text { servicing can be scheduled to prevent any fleet downtime. In } \\
\text { addition, by learning the driving behavior of the fleet driver, } \\
\text { customized driving tips for the drivers' improvement can be } \\
\text { provided. Through an effective driving and maintenance, it can } \\
\text { reduce the CO }{ }^{2} \text { emissions and prolong the vehicle life } \\
\text { expectancy. }\end{array}$ \\
\hline $\begin{array}{l}\text { Agriculture (Minbo, } \\
\text { Zhu, \& Guangyu, } \\
\text { 2013) }\end{array}$ & $\begin{array}{l}\text { SMEs in the agriculture line of business can employ the use of } \\
\text { the sensory application to track the soil and air temperature, } \\
\text { humidity, speed, leaf wetness, rainfall, and fruit color. The } \\
\text { farmers can, in turn, use the collected data, to amendment } \\
\text { accordingly the watering amount, time and the picking }\end{array}$ \\
\hline
\end{tabular}




\begin{tabular}{|l|l|}
\hline & schedules. \\
\hline $\begin{array}{l}\text { Medical (Wang, } \\
\text { Wang, Zhang, \& }\end{array}$ & $\begin{array}{l}\text { Within the medical context, the use of IoT can enable the medical } \\
\text { doctors and hospitals to collect real-time information on the } \\
\text { patient's data using wearable gadgets or home health's monitors. } \\
\text { Medical doctors can utilize the real-time data collected to } \\
\text { monitor and improve the patient care. In addition, provide better } \\
\text { diagnosis and treatment. }\end{array}$ \\
\hline
\end{tabular}

Based on the examples provided, it is evident that the application of BDA and IoT are implementable in various sector and industries. For an example, from streamlining the supply chain cycle, enhancing the business product and services, managing operational efficiencies and many more. It is important to highlight that for the application of BDA and IoT to be carried out; the need for connectivity is an important element. The data collected from the devices and remote sensors need to be converging with at least one of the SME's management system for the information to be processed and reported in the system's dashboard. The SMEs companies can explore the integration platform with in-memory computing functionalities to furnish real-time processing of the large volume of data churned out by the IoT systems. In summation, as recount earlier, the BDA and IoT application would provide vast opportunities for the SMEs' business growth.

\section{TECHNOLOGY READINESS FOR BDA-IOT}

Technology readiness refers to the organisational's employees proneness to adapt and accept the usage of new technology in order to achieve work or home life goals (Parasuraman \& Grewal, 2000). In theory, there are four core elements that constitute technology readiness insecurity, innovativeness, optimism and discomfort. Optimism is defined as the positive effect of new technology on the user lives which he or she has control over it. Innovativeness refers to individuals that are positive towards new technology adoption. Discomfort is the opposite of the classification of optimism whereby the individual would discern new technology adoption as overwhelming. Lastly, insecurity refers to the negative reaction and perception towards new technology, assuming that the new technology will not function effectively as intended (Godoe \& Johansen, 2012). It is suggesting that the innovativeness and optimism elements act as key motivators in embracing new technology application, whereby, the elements of insecurity and discomfort are deterrence factors (Parasuraman \& Colby, 2015).

There are two related measurements available in measuring the scale of technology readiness - technology readiness index (Probst et al.) and technology readiness level (TRL). First and foremost, it is important to distinguish that TRI and TRL serve two different purposes and usage. TRI is being measured using a marketing-based measurement scale, which uses the survey to retrieve the individual feedback towards new technology adoption within the service domain - for instance, using the Internet platform (Parasuraman \& Grewal, 2000). Unlike the TRI, TRL measurement is technical-based centric which is used to evaluate the maturity level of a specific technology and making a comparison against other various types of technology for instance, NASA is applying it for its technology planning task (Clausing \& Holmes, 2010). It is fundamental for SMEs to assess its technology readiness before galvanizing into the BDAIOT implementation.

\section{CONCLUSION}

Based on the study of this chapter, it is evident that IoT is set to revolutionize the business environment. And due to IoT, the collection of data is envisioned to grow rapidly as it is 
already. It is further evidential that data is the new oil and asset for companies in this 21st century. When the data are processed and translated, it can provide companies with unique and new insights into enhanced strategic decision making and forecasting. Despite the momentous opportunities and advantages of advanced technologies, the SME businesses groups are slow in its adoption. From this study, it was uncovered that the key resistant factors towards BDA application are within the aspect of knowledge, resources and data governance. An additional organisational barrier like organisational decision-making, structure and culture further raises the resistant factors of the SMEs in the application BDA in its business. It is key that the SME businesses are acquainted with the BDA application, as the presence of IoT will further generate a massive volume of data. And these data will need to be analysed in order to create value for the SMEs. Through this chapter, two opportunities of IoT platform that the SMEs can explore are the cyber-physical cloud computing (CPCC) and mobile crowdsensing (MCS) platforms. The probable challenges of IoT and BDA, on the other hand, includes resource limitations, cybersecurity and privacy and the heterogeneous state of the data collected. The overall encapsulation of this chapter identifies that BDA and IoT application are not only limited to the large organization but rather, it also provides tremendous opportunities for SMEs - and this is evident with the several industrial application provided. The SMEs can be equivalently competitive and yet remaining small by channeling its focus over technology and applications over its headcount. The opportunity to tap on both the BDA and IoT capabilities is limitless. In order to measure the scale of technology readiness before the application of BDA and IoT, SMEs can adopt either one or both the technology readiness measurement method. There is technology readiness index (Probst et al.) and technology readiness level (TRL). It is fundamental for SMEs to assess its technology readiness before galvanizing into the BDA-IoT implementation to ensure that the organization is equipped to implement the BDA-IoT application. In conclusion, as much as there are immense opportunities of entry for the SMEs to tap on the BDA-IoT - the SMEs will need to step out of its comfort zone and be willing to explore the potential of new advanced technologies. This is key in order to remain relevant and competitive in the ever-changing business environment.

\section{REFERENCES}

Arora, B., \& Rahman, Z. (2016). Using Big Data Analytics for Competitive Advantage. INTERNATIONAL JOURNAL OF INNOVATIVE RESEARCH \& DEVELOPMENT, 5(2).

Bagnoli, V. (2015). Competition for the Effectiveness of Big Data Benefits. IIC-International Review of Intellectual Property and Competition Law, 46(6), 629-631.

Bandyopadhyay, D., \& Sen, J. (2011). Internet of things: Applications and challenges in technology and standardization. Wireless Personal Communications, 58(1), 49-69.

Beyer, M. (2011). Gartner Says Solving'Big Data'Challenge Involves More Than Just Managing Volumes of Data. Gartner. Archived from the original on, 10.

Capgemini. (2012). Measuring Organizational Maturity in Predictive Analytics: the First Step to Enabling the Vision | Resource. 
Chen, S., Xu, H., Liu, D., Hu, B., \& Wang, H. (2014). A Vision of IoT: Applications, Challenges, and Opportunities With China Perspective. IEEE Internet of Things Journal, 1(4), 349359. doi:10.1109/JIOT.2014.2337336

Chudik, A., Kapetanios, G., \& Pesaran, M. H. (2016). Big Data Analytics: A New Perspective. Federal Reserve Bank of Dallas Globalization and Monetary Policy Institute.

Chunli, L. (2012, 21-23 April 2012). Intelligent transportation based on the Internet of Things. Paper presented at the 2012 2nd International Conference on Consumer Electronics, Communications and Networks (CECNet).

Clausing, D., \& Holmes, M. (2010). Technology readiness. Research-Technology Management, 53(4), 52-59.

Coleman, S., Göb, R., Manco, G., Pievatolo, A., Tort-Martorell, X., \& Reis, M. S. (2016). How Can SMEs Benefit from Big Data? Challenges and a Path Forward. Quality and Reliability Engineering International. doi:10.1002/qre.2008

Coleman, S. Y. (2016). Data-Mining Opportunities for Small and Medium Enterprises with Official Statistics in the UK. Journal of Official Statistics, 32(4), 849-865. doi:10.1515/jos-2016-0044

Colombo, A. W., Bangemann, T., Karnouskos, S., Delsing, J., Stluka, P., Harrison, R., . . Lastra, J. L. (2014). Industrial cloud-based cyber-physical systems. The IMC-AESOP Approach.

Commission, E. (2013). Business Opportunities: Big Data.

Commission, E. (2017). Annual Report on European SMEs 2015/2016 - SME recovery continues.

Culkin, N., \& Smith, D. (2000). An emotional business: a guide to understanding the motivations of small business decision takers. Qualitative Market Research: An International Journal, 3(3), 145-157. 
Ganti, R. K., Ye, F., \& Lei, H. (2011). Mobile crowdsensing: current state and future challenges. IEEE Communications Magazine, 49(11).

Godoe, P., \& Johansen, T. (2012). Understanding adoption of new technologies: Technology readiness and technology acceptance as an integrated concept. Journal of European Psychology Students, 3(1).

Goebel, R., Norman, A., \& Karanasios, S. (2015). Exploring the Value of Business Analytics Solutions for SMEs. Association for Information Systems AIS Electronic Library (AISeL).

Lacey, D., \& James, B. E. (2010). Review of availability of advice on security for small/medium sized organisations. Retrieved, 2(28), 2013.

Lee, I., \& Lee, K. (2015). The Internet of Things (IoT): Applications, investments, and challenges for enterprises. Business Horizons, 58(4), 431-440.

Lugmayr, A., Stockleben, B., Scheib, C., Mailaparampil, M., Mesia, N., \& Ranta, H. (2016). A Comprehensive Survey on Big-Data Research and its Implications-What is Really'New'in Big Data?-IT's Cognitive Big Data! Paper presented at the PACIS.

Minbo, L., Zhu, Z., \& Guangyu, C. (2013). Information Service System Of Agriculture IoT. Automatika, 54(4), 415-426. doi:10.7305/automatika.54-4.413

Mohd Selamat, S. A., Prakoonwit, S., Sahandi, R., Khan, W., \& Ramachandran, M. (2018). Big data analytics -A review of data - mining models for small and medium enterprises in the transportation sector. Wiley Interdisciplinary Reviews: Data Mining and Knowledge Discovery, 8(3), e1238.

Parasuraman, A., \& Colby, C. L. (2015). An updated and streamlined technology readiness index: TRI 2.0. Journal of service research, 18(1), 59-74. 
Parasuraman, A., \& Grewal, D. (2000). The impact of technology on the quality-value-loyalty chain: a research agenda. Journal of the academy of marketing science, 28(1), 168174.

Perera, C., Liu, C. H., Jayawardena, S., \& Chen, M. (2014). A survey on internet of things from industrial market perspective. IEEE Access, 2, 1660-1679.

Porter, M. E., \& Heppelmann, J. E. (2014). How smart, connected products are transforming competition. Harvard business review, 92(11), 64-88.

Probst, L., Frideres, L., Demetri, D., Vomhof, B., Lonkeu, O.-K., \& Luxembourg., P. (2014). Business Innovation Observatory - Customer Experience. European Union.

Riggins, F. J., \& Wamba, S. F. (2015). Research directions on the adoption, usage, and impact of the internet of things through the use of big data analytics. Paper presented at the System Sciences (HICSS), 2015 48th Hawaii International Conference on.

Rights, E. U. A. f. F. (2016). Handbook on European data protection law. Retrieved from http://fra.europa.eu/en/publication/2014/handbook-european-data-protection-law

Shanthamallu, U. S., Spanias, A., Tepedelenlioglu, C., \& Stanley, M. (2017). A brief survey of machine learning methods and their sensor and loT applications. Paper presented at the Information, Intelligence, Systems \& Applications (IISA), 2017 8th International Conference on.

Strohbach, M., Ziekow, H., Gazis, V., \& Akiva, N. (2015). Towards a big data analytics framework for loT and smart city applications Modeling and processing for nextgeneration big-data technologies (pp. 257-282): Springer.

Sun, C. (2012). Application of RFID technology for logistics on internet of things. AASRI Procedia, 1, 106-111. 
Sun, Y., Song, H., Jara, A. J., \& Bie, R. (2016). Internet of things and big data analytics for smart and connected communities. IEEE Access, 4, 766-773.

Tao, F., Cheng, Y., Da Xu, L., Zhang, L., \& Li, B. H. (2014). CCloT-CMfg: cloud computing and internet of things-based cloud manufacturing service system. IEEE Transactions on Industrial Informatics, 10(2), 1435-1442.

Turban, E., King, D., Sharda, R., \& Delen, D. (2013). Business intelligence: a managerial perspective on analytics: Prentice Hall, New York.

UK, E.-s. (2013). Big data analytics: adoption and employment trends, 2012-2017.

Van Kranenburg, R., \& Bassi, A. (2012). IoT challenges. Communications in Mobile Computing, 1(1), 9.

Wang, X., Wang, J. T., Zhang, X., \& Song, J. (2013, 20-21 June 2013). A multiple communication standards compatible loT system for medical usage. Paper presented at the 2013 IEEE Faible Tension Faible Consommation.

Woodward, W. A., Gray, H. L., \& Elliott, A. C. (2017). Applied Time Series Analysis with R: CRC press.

Zhou, J., Cao, Z., Dong, X., \& Vasilakos, A. V. (2017). Security and privacy for cloud-based IoT: Challenges. IEEE Communications Magazine, 55(1), 26-33. 